http://dx.doi.org/10.1590/0370-44672014700060

\section{Rovadávia Aline de Jesus Ribas \\ Professora Efetiva \\ Universidade Federal de Ouro Preto - UFOP \\ Escola de Minas \\ Departamento de Engenharia Civil - DECIV \\ Ouro Preto - Minas Gerais - Brasil \\ roviaaline@gmail.com}

\author{
Henor Artur Souza \\ Professor Titular \\ Universidade Federal de Ouro Preto - UFOP \\ Escola de Minas \\ Departamento de Engenharia de Controle e \\ Automação e Técnicas Fundamentais - DECAT \\ Ouro Preto - Minas Gerais - Brasil \\ henorster@gmail.com
}

\title{
Acoustical and thermal performance of multilayer closing panels used in steel-structured buildings
}

\begin{abstract}
This article provides an evaluation of the acoustical and thermal performance of some closing systems by referencing materials such as cement plates, plasterboard walls, precast concrete panels and expanded polystyrene. Reverberation time is calculated by applying an empirical formula, which uses temperature and relative air humidity values obtained from simulations that were conducted using the computational simulation program ESP-r (Energy Simulation Program-research). The internal temperature presented by the ESP-r is an indicator of thermal performance. Using a simplified graphic method, the acoustical performance is also evaluated by estimating the loss of sound transmission that occurs through the closing panels. Combinations of these panels, which form multilayer panels mediated by a layer of air and with or without insulating material between them, are applied. The results show that multilayered closing systems, when filled with insulating material, are an efficient solution than can provide adequate acoustical and thermal performance.
\end{abstract}

Keywords: building acoustics. steel-structured buildings. closing panels. acoustical and thermal performance.

The use of multilayer closing systems, systems composed of two panels mediated by a layer of air and insulating material, can result in superior acoustical performance. High-quality performance is linked to an increase in noise transmission loss without requiring high cost or significant material accumulation. Thus, sound transmission loss through a wall, and reverberation time within an environment because of existing people, air and surfaces may be acoustical performance indicators of locks. However, these closing systems have low thermal inertia, which may compromise their thermal performance and require an integrated study of their thermal and acoustical performance (BIES; HANSEN,

by Citherlet (2001), which uses simulated values for temperature and relative air humidity obtained through the computational program ESP-r (Energy Simulation Program - research). The $R T$ is calculated by using the building
2003; RIBAS; SOUZA, 2011).

The purpose of this paper is to conduct a thermal and acoustical evaluation of the performance of some multilayer closing systems that are used in the construction of steel structures in Brazil. Examples of these systems include cement plates, plasterboard walls, precast concrete panels and expanded polystyrene. The study has been performed on composed panels (multilayer system) with and without insulating material. An estimation was conducted to determine the sound transmission loss (TL), which occurs through the closings, and reverberation time $(R T)$ and temperature $\left(T_{i}\right)$, which occur in the environment.

\section{Materials and methods}

An estimation of $T L$ is made through a simplified graphical method presented by Sharp (1973) and analyzed by Bies and Hansen (2003) and Bistafa (2006). The RT is calculated from an empirical formulation devised 


\subsection{Sound transmission loss ( $T L)$}

The loss in sound transmission $(T L)$, which occurs when sound arrives at the other side of a wall with a lower intensity

where $f$ is the frequency of the incident wave $(\mathrm{Hz})$ and $M$ is the surface density of the wall material $\left(\mathrm{kg} / \mathrm{m}^{2}\right)$.

In a single wall, the sound transmission loss is influenced by the frequency of the incident sound $(f)$ exhibiting different resonance and vibration than the original sound is a characteristic of sound insulation and the closure may indicate its acoustical performance (BIES;

$$
T L=20 \log (f . M)-47.4
$$

behavior, depending on the wall's mass and stiffness. The TL of simple isotropic panels (solid and homogeneous) can be obtained from experimentational or standard essays or can also be estimated as a function of critical frequency, $f_{c}$, Eq. (2), by applying the simplified graphical
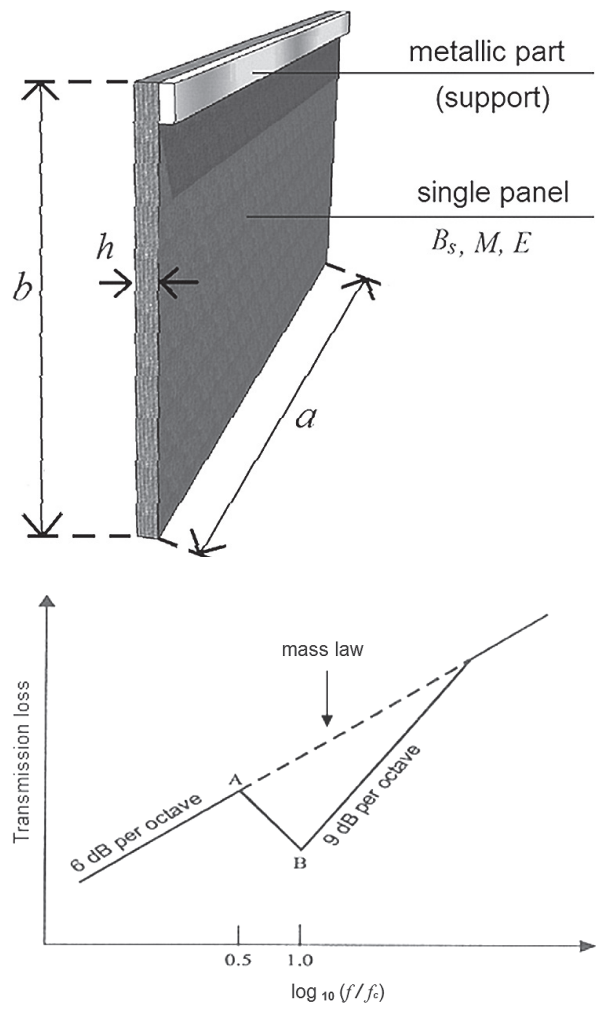

HANSEN, 2003; BISTAFA, 2006). Gerges (2000) presents Eq. (1) for the calculation of the $T L$, called mass law:

method to one idealized model composed of one panel with dimensions $a, b$ and $h$, bending stiffness $\left(B_{s}\right)$, Eq. (2), and module of elasticity $(E)$, as shown in the Figs. 1 and 2. This method considers the simply supported panel, which limits its applicability (BISTAFA, 2006).

Figure 1

Idealized model of an isotropic simply supported panel.

Figure 2

Estimation of the $T L$ through simple isotropic panels (BIES; HANSEN, 2003).

$$
f_{c}=\frac{c^{2}}{2 \pi} \sqrt{\frac{M}{B_{s}}}(\mathrm{~Hz}) \text { and } B_{s}=\frac{E h^{3}}{12} \quad \text { (N.m) }
$$

where $c$ is the speed of sound wave in air $(\mathrm{m} / \mathrm{s}) ; M$ is the surface density of the material panel $\left(\mathrm{kg} / \mathrm{m}^{2}\right) ; B_{s}$ is the panel's bending stiff- ness (N.m), given by Eq (2), $E$ is the module of elasticity of the material $\left(\mathrm{N} / \mathrm{m}^{2}\right)$ and $h$ is the thickness of the panel (m).
The points $A$ and $B$ in Fig. 3 have coordinates $\left(0.5 f_{c} ; T L_{A}\right)$ and $\left(f_{c} ; T L_{B}\right)$, respectively, calculated by Eq. (3).

$$
T L_{A}=20 \log \left(f_{c} \cdot M\right)-54 \quad(\mathrm{~dB}) \quad \text { and } \quad T L_{B}=20 \log \left(f_{c} \cdot M\right)+10 \log \eta-45 \quad(\mathrm{~dB})
$$

where $\eta$ is internal damping factor of the panel (non-dimensional). After the point $B$ and $f_{c}$, the TL is given by Eq. (4), valid for $f>f_{c}$, applied until the frequency to which the $T L$ is calculated by the mass law, Eq. (1).

$$
T L=20 \log (f \cdot M)+10 \log \left(\eta \frac{f}{f_{c}}\right)-45
$$

Closing systems with double walls may produce more sound insulation than those produced by systems with simple walls, provided the walls are of the same thickness, Fig.3. Due to the complexity of the sound energy transmission between the panels, the acoustical insulation is not equivalent to the sum of the indi- vidual acoustical insulation values. Bies and Hansen (2003) and Bistafa (2006) present a simplified graphical method to estimate the $T L$ of doubled walls. The 
method, which is based on Sharp's analysis (1973), considers that panel fixation is determinant on the efficiency of their sound transmission (GERGES, 2000; HASSAN, 2009).

The panels can be fixed to the same scantling or metallic profile through resilient bars in an effort to reduce the mechanical vibrations. There are two common approaches to fixing the panels that result in four possible combinations. When the panel is fixed directly to the

Figure 3

Diagram of the closing systems: with absorber material.

Figure 4

Estimation of $T L$ through double walls (BIES; HANSEN, 2003; BISTAFA, 2006).

Table 1

Coordinates of the

points $A, B$ and $C$ to line-line fixation.

where $f_{o}$ is the lowest frequency of resonance from the set mass-air-mass $(\mathrm{Hz}) ; T L_{i}$ is the transmission loss at the point $i(\mathrm{~dB})$; $d$ is the spacing among the

\subsection{Reverberation time (RT)}

The $R T$ can indicate the acoustical performance of a closing and it depends on the frequency of emission, the capacity of the surrounding material to absorb this frequency, the volume of the present air

scantling or metallic profile, one line of contact is created between these two elements to create the fixation in line. The spacing among the scantlings or profiles (b), Eq. (8), should be uniform. The four possible combinations of fixation are lineline, line-punctual, punctual-line, and punctual-punctual. In the case of fixation in line or punctual fixation, the simplified graphical method is applied when the panels are fixed to the same scantling or metallic profile. Through formulation,
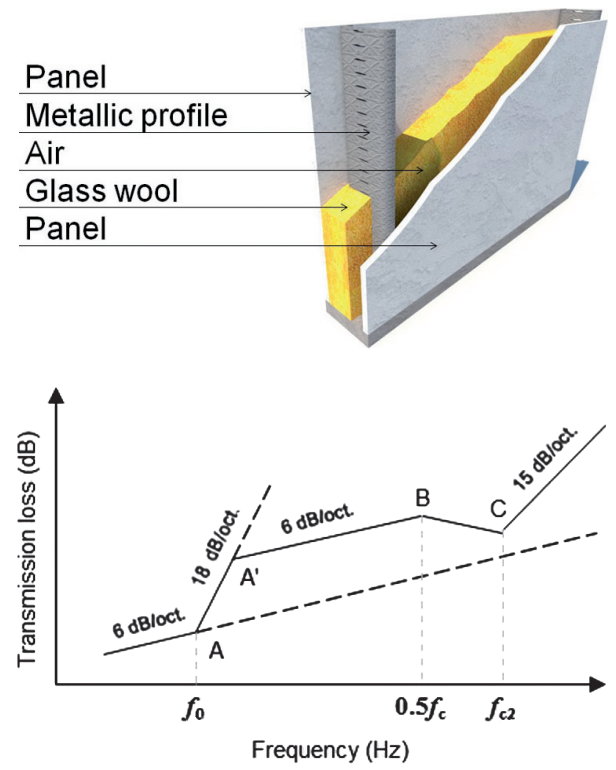

Point/co-ordinates Equations

$$
\begin{array}{cl}
A & f_{0}=80\left(\frac{M_{1}+M_{2}}{d M_{1} M_{2}}\right)^{1 / 2} \\
\left(f_{0} ; T L_{A}\right) & T L_{A}=20 \log \left(M_{1}+M_{2}\right)+20 \log f_{0}-48
\end{array}
$$

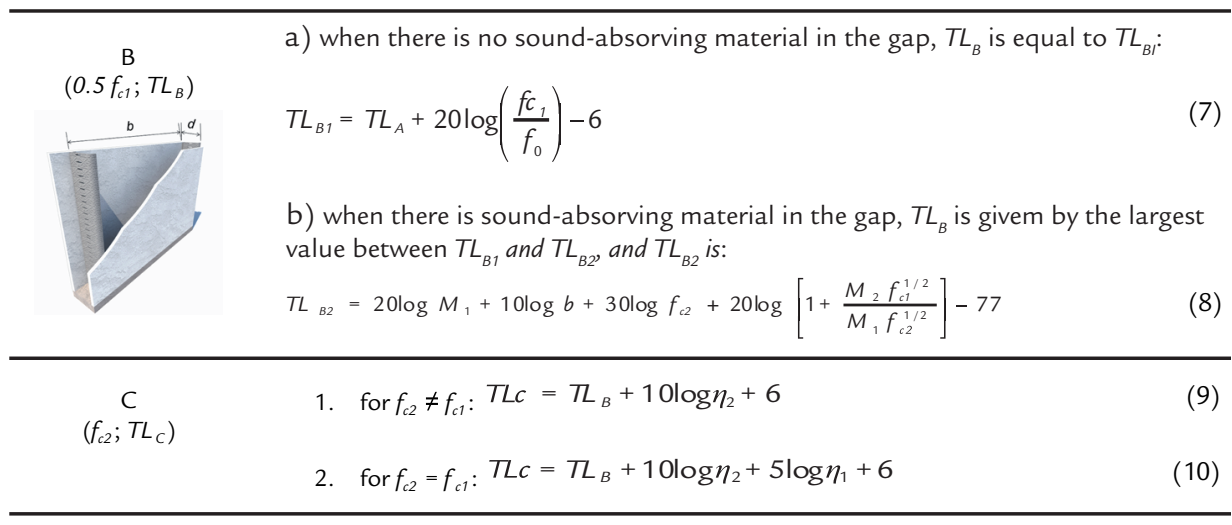

panels or deepening of the cavity $(\mathrm{m})$; $M_{i}$ is the surface density of the panel $i\left(\mathrm{~kg} / \mathrm{m}^{2}\right) ; f_{c i}$ is the critical frequency of the panel $i(\mathrm{~Hz})$, seen in Eq. (2);

and the spectrum of the sound frequencies. It is characterized by the absorption due to the closing (wrapper), the furniture, the persons and the existing air in the room (BIES; HANSEN, 2003; HASSAN, 2009; the coordinates of the points $\mathrm{A}, \mathrm{B}$ and $\mathrm{C}$ are determined through estimation of the coordinates from point A' (Fig. 4). The formulation applied through the simplified graphical method to determine the $T L$ curve, based on line-line fixation, is shown in Table 1, Eq. (5) to (10). In the formulation, number 1 is associated with the panel that generates the smallest $f_{c}$, and number 2 is associated with the remaining panel (BIES; HANSEN, 2003; BISTAFA, 2006). 
building, which absorbs the internal noise, is required. Sabine defined the RT by the

Eq. (11), in 1896 (CITHERLET, 2001; BISTAFA, 2006).

$$
R T=0.161 \cdot \frac{V}{A_{f}^{t}}
$$

where $V$ is the volume of the room $\left(\mathrm{m}^{3}\right)$; $f$ is the considered frequency $(\mathrm{Hz})$; and $A_{f}^{t}$ is the total area equivalent to the room to the frequency $f\left(\mathrm{~m}^{2}\right)$. The total area equivalent $\left(A_{f}^{t}\right)$ is defined by the sum shown in Eq. (12) (CITHERLET,
2001; HASSAN, 2009; KNUDSEN; HARRIS, 1978).

$$
A_{f}^{t}=A_{f}^{\text {fech }}+A_{f}^{o b j+p e s}+A_{f}^{a r}=\sum_{i}^{\text {fech }}\left(S_{i} \cdot \alpha_{i, f}^{\text {Sab }}\right)+\sum_{j}^{o b j}\left(N_{j} \cdot A_{j, f}^{o b j}\right)+\sum_{k}^{\text {pes }}\left(P_{k} \cdot A_{k, f}^{\text {pess }}\right)+4 m V \quad\left(\mathrm{~m}^{2}\right)
$$

where $A_{f}^{\text {fech }}$ is the area of equivalent absorption of the closing in the interior of the room ( $\mathrm{m}^{2}$ Sabine); $A_{f}^{o b j+p e s}$ is the absorption equivalent of the objects and persons in the interior of the room $\left(\mathrm{m}^{2}\right)$; $A_{f}^{a r}$ is the equivalent absorption due to the air in the interior of the room $\left(\mathrm{m}^{2}\right)$

should be considered at frequencies equal or above $1000 \mathrm{~Hz}$; $S$ is the area of the internal surface $\mathrm{i}$ of the room $\left(\mathrm{m}^{2}\right) ; \alpha_{i f}^{\text {sab }}$ is the Sabine's coefficient of absorption of surface $i$ in the frequency $f ; N_{j}$ is the number of occurrences of the object like $j, A_{j, f}$ obj is the equivalent area of ab-

sorption of the object $\mathrm{j}$ in the frequency $f\left(\mathrm{~m}^{2}\right) ; P_{k}$ is the number of occurrences of the person $k$; and $A_{k, f}$ pes is the equivalent area of absorption of the person $k$ in the frequency $f\left(\mathrm{~m}^{2}\right) ; m$ is the coefficient of the sound absorption of the air $\left(\mathrm{m}^{-1}\right) ; V$ is the volume of the room $\left(\mathrm{m}^{3}\right)$.

\subsection{Acoustical and thermal performance}

Quantify acoustical performance is an essential step to improve the isolation of an environment. So standards are designed to establish reference values that aim to provide sound insulation to the environment ideal for the activity there developed (BIES; HANSEN, 2003; DUARTE; MOORHOUSE; VIVEIROS, 2012).

The reverberation time should be based on the use of the room, as inadequate values may disrupt the intelligibility or quality of speech. The higher the volume in the room and the greater number of low-absorbing materials used, the higher will be the duration of the reverberation. If the reverberation continues in the envi-

ronment for a significant length of time, it may overcompensate the position of syllabi and/or musical notes; if it disappears altogether, some sound sources may not be perceived at all (MAEKAWA; RINDEL; LORD, 2011).

Because spaces where speech and verbal communication is anticipated (classrooms, conference spaces and theatres) require smaller reverberation times, ideally, the reflected sound decreases rapidly to prevent interference with direct sound and does not reduce its intelligibility. For a small room, a reverberation time of $0.5 \mathrm{~s}$ is adequate. However, a longer time is necessary for concert halls because the reverberation until a certain point is required to ensure that acoustical quality in orchestral music is not compromised (MEHTA; JOHNSON; ROCAFORT, 1999; BISTAFA, 2006).

According to the Brazilian Standard NBR 15575 (ABNT, 2013), a closing system must have appropriate acoustical insulation to aerial external noises, by impacts and among environments. The minimum thermal performance in summer in Brazil is verified when $T_{i, \max } \leq T_{e \text { max }}$, where $T_{i, \max }$ is the maximum value of the air temperature registered in the edifice $\left({ }^{\circ} \mathrm{C}\right)$ and $\mathrm{T}_{e, \max }$, is the maximum value of the external air temperature registered.

\section{Results}

\subsection{Estimate of the $T L$}

An estimation of the $T L$ is made for multilayer closing systems, which consist of combinations of cement plates (PLC),

plasterboard walls (GEA), precast concrete panels (PMC) and expanded polystyrene (EPS), with or without sound absorber mate-

\begin{tabular}{c|c|c|c|c|c} 
Material & $E\left(\mathrm{~N} / \mathrm{m}^{2}\right)$ & $\rho\left(\mathrm{kg} / \mathrm{m}^{3}\right)$ & $\eta$ & $B_{s}(\mathrm{~N} . \mathrm{m})$ & $f_{c}(\mathrm{~Hz})$ \\
\hline $\operatorname{PLC}(10)$ & $1.2 \times 10^{8}$ & 1330 & 0.005 & 83 & 21158 \\
\hline GEA $(12.5)$ & $2.0 \times 10^{9}$ & 750 & 0.006 & 339 & 3113 \\
\hline PMC $(75)$ & $2.3 \times 10^{10}$ & 2400 & 0.020 & 842285 & 274 \\
\hline $\operatorname{EPS}(100)$ & $2.5 \times 10^{6}$ & 960 & 0.005 & 210 & 12670 \\
\hline
\end{tabular}

The dimension $b$ is assumed equal to $0.60 \mathrm{~m}$ and the fixation is line-line. One of the closing systems is fictitious, for example, the use of the plasterboard as an external closing. However, it is applied to the simulations for comparison with other situations. rial in the panel air cavity. Glass wool (LVI) is preferred. The acoustical features of the panel materials are shown in the Table 2 .

Table 2

Acoustic features of the panel materials.

The EPS panel is formed with mortar that is $22.5 \mathrm{~mm}$ thick and EPS that is $55 \mathrm{~mm}$ thick and mortar that is $22.5 \mathrm{~mm}$ thick.

\subsection{The thermal simulation and the calculation of the $R T$}

The time value of the tempera- ture $\left(T_{i}\right)$ and the relative humidity of the air $\left(h_{r}\right)$ are obtained through nu- 
merical simulation. The building, with an area of $54 \mathrm{~m}^{2}$, is divided into four

Figure 5

Basic plant (a) and perspective

(b) of the building, generated by ESP-r.

For the configuration of each space, the internal and external closings are varied during the simulations, the materials in Table 3 are applied and the compositions of the other closing materials and the thickness are: the ground: ceramic material (10), mortar (20) and concrete base (80); the cement slab: cellular autoclaved (CCA) (140), composed by one concrete layer (20), CCA (100) and total internal redressing in mortar (20); covertures: ceramic tile (10); windows: common transparent glass (4); external door: wood with medium specific mass (25); internal door: compensated wood (25); closing of bath: wall (105) composed by PLC(10)-air(75)-

$T L$ and $R T$ as a function of frequency - PLC.
Figure 6

Figure 7

$T L$ and $R T$ as a function of frequency - GEA.

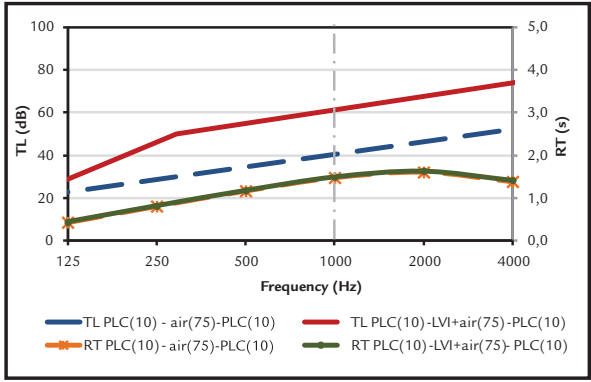

PLC(10) and ceramics (10).

The presence of persons, lamps turned on and equipment gaining casual heat (sensible and latent) was not considered. For air flow, a rate of renewal equal to $3 \mathrm{ren} / \mathrm{h}$ is adopted (ABNT, 2013). For the characterization of the weather conditions, the weather zoning presented by the Brazilian Standard NBR 15220 (ABNT, 2005) was adopted. Data for one typical summer day from zone three were used (13/01/2000) with the city of Belo Horizonte used as a reference (latitude - 19.85 and longitude-43.9). Other data utilized in the simulations (medium values) are the following: variation of sun radiation
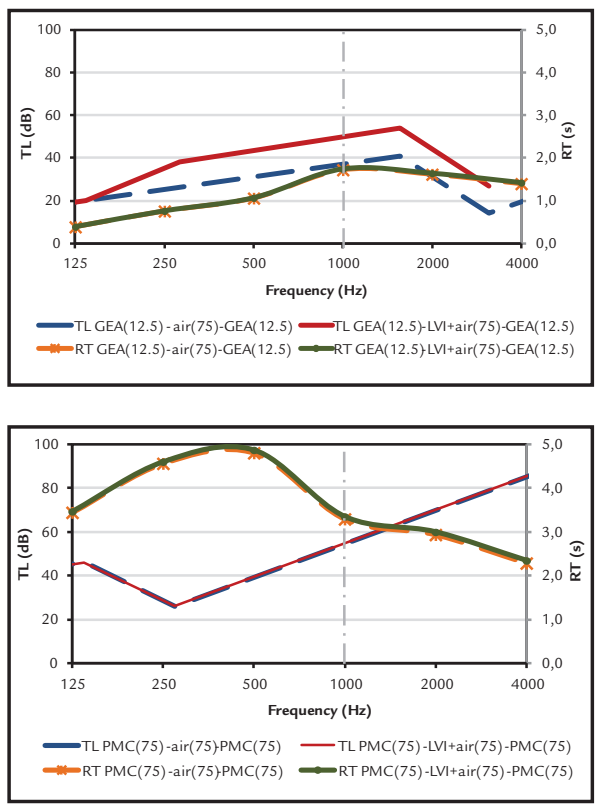

height of $3.00 \mathrm{~m}$ and total height of $4.20 \mathrm{~m}$, Fig. 5 .

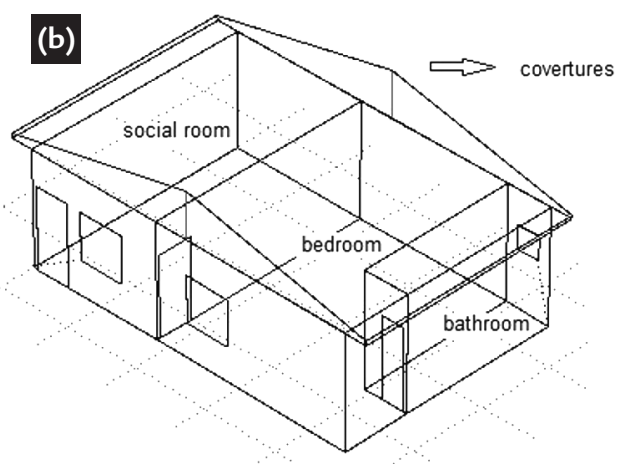

incident for a horizontal plan $(R S)$ equal 97.71 W/m², dry bulb temperature (TBS) equal $24.47^{\circ} \mathrm{C}$, sun radiation incident for a normal direction $\left(R S_{\text {Total }}\right)$ equal $299.08 \mathrm{~W} /$ $\mathrm{m}^{2}$, predominant wind speed and direction equal $1.68 \mathrm{~m} / \mathrm{s}$ e $77.5^{\circ}$ (time sense from North), and relative air humidity $\left(h_{r}\right)$ equal $63.13 \%$.

The variation of the $T L$ and of the $R T$, as a function of frequency and at 14:30 when the temperature reaches $27.5^{\circ} \mathrm{C}$, for the social room, is illustrated by curves in Fig. 6 to 11. The variation of the $T_{i}$ and of the $R T$, as a function of time and at a frequency of $1000 \mathrm{~Hz}$, is shown in the curves in Fig. 12 to 17. 

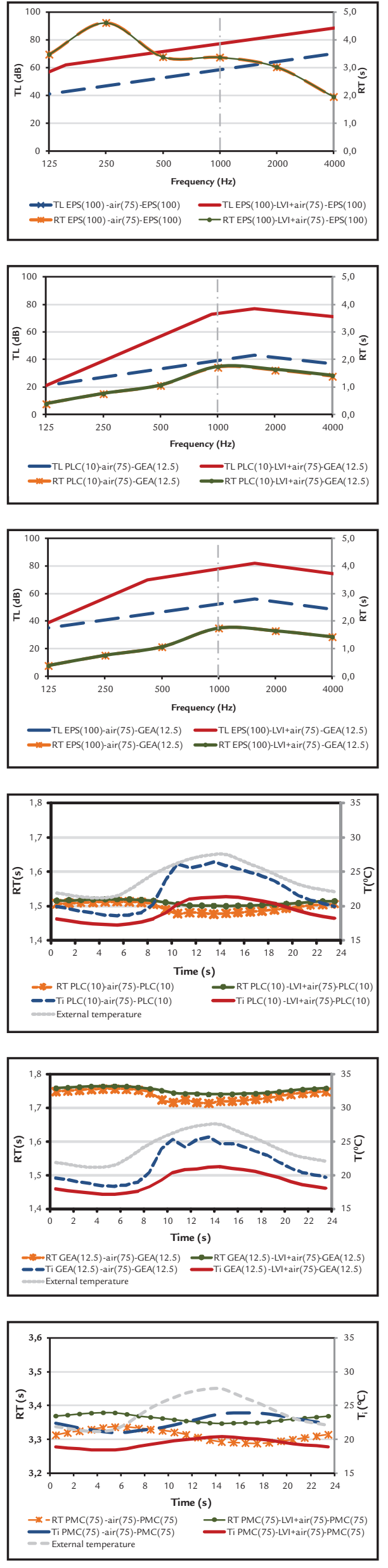

Figure 9

$T L$ and $R T$ as a function of frequency - EPS.

Figure 10

$T L$ and $R T$ as a

function of frequency - PLC-GEA.

Figure 11

TL and RT as a

function of frequency - EPS-GEA.

Figure 12

$R T$ and $T_{i}$ as a

function of time $(1000 \mathrm{~Hz})-\mathrm{PLC}$.

Figure 13

$R T$ and $T_{i}$ as a

function of time $(1000 \mathrm{~Hz})-\mathrm{GEA}$.

Figure 14

$R T$ and $T_{i}$ as a

function of time $(1000 \mathrm{~Hz})$ - PMC. 
Figure 15

$R T$ and $T$ as a function of time $(1000 \mathrm{~Hz})$-EPS.

Figure 16

$R T$ and $T_{i}$ as a

function of time $(1000 \mathrm{~Hz})$ - PLC-GEA.

Figure17

$R T$ and $T_{i}$ as a

function of time - $(1000 \mathrm{~Hz})$-EPS-GEA

\section{Analysis and conclusion}

The use of an insulating material in a closing system has the potential to cause an increase in the $T L$ and a decrease in the $T_{i}$; however, results indicate that it does not exert a substantial influence on the $R T$. In the frequency range considered here, the $T L$ is higher for the PLC(10)-LVI+air(75)-GEA(12.5) when considering the closings in PLC and GEA and for the EPS(100)-LVI+air(75)EPS(100) in the other closings. The closings in PLC and EPS exhibit the mass law behavior for a wide range of frequency. The other closings exhibit behaviors in the regions controlled by resonance and coincidence.

When considering the $1000 \mathrm{~Hz}$ in the social room wall, each of the analyzed closings conform to the criterion recommended by the Brazilian Standard NBR 15575 (ABNT, 2013) of a TL greater
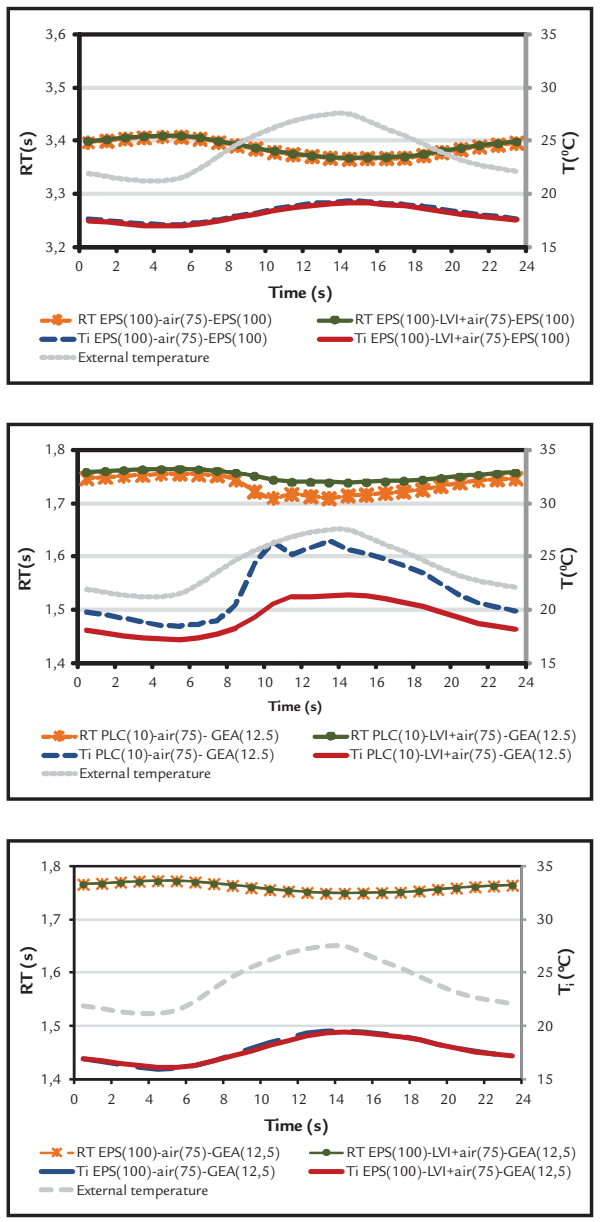

than $35 \mathrm{~dB}$. The fulfilled closings with LVI resulted in better performance, and the lowest values of TL were observed at GEA(12.5)-LVI+air(75)-GEA(12.5), Fig. 6 to 11 .

In the reference building model, with an equivalent frequency $(1000 \mathrm{~Hz})$, the PLC presents the higher coefficient of sound absorption. To this frequency, the closings resulted in values of $R T$ greater than the recommended value of $0.5 \mathrm{~s}$ for a small room designated for speech (Fig. 6 to 11). Note that the presence of persons and furniture are not being considered as housing; this omission creates the tendency to reduce the area of sound absorption inside the space, which increases the RT value. When comparing the performance of the closings in reference to the $R T$, it is observed that the closings constituted by PLC, GEA,
PLC-GEA and EPS-GEA show a smaller RT than others.

With respect to thermal performance, all the analyzed closings meet the criterion recommended by Brazilian Standard NBR 15575 (ABNT, 2013) of $T_{i, \max } \leq T_{e, \max }$. The $T_{i}$ is smaller for the closings formed by EPS and EPS-GEA, but the $R T$ is higher. Considering the $R T$ and $T$, the PMC(75)-LVI+air(75)-PMC demonstrates superior performance (Fig. 12 to 17 ).

From the depicted results, the double closing system PLC(10)-LVI+air(75)-PLC(10) displays great acoustical and thermal performance. This study has illustrated that when choosing the most appropriate closing system for a building, it is necessary to perform a comparison between the results of the analyses in the frequency range of interest.

\section{Acknowledgments}

The authors gratefully acknowledge the UFOP, FAPEMIG and the CNPq, Brazil.

\section{References}


nho térmico de edificações, Rio de Janeiro, 2005, 92 p. (in Portuguese)

ASSOCIAÇÃO BRASILEIRA DE NORMAS TÉCNICAS. NBR 15575: Edifícios habitacionais - Desempenho, Rio de Janeiro, 2013, 312 p. (in Portuguese)

BIES, D.A., HANSEN, C.H. Engineering noise control: theory and practice. 3th ed. London and New York: Spon Press, 2003. 719 p.

BISTAFA, S.R. Acústica aplicada ao controle de ruído. São Paulo: Edgard Blücher, 2006. 368 p. (in Portuguese)

CITHERLET, S. Towards the holistic assessment of building performance based on an integrated simulation approach. Swiss Federal Institute of Technology (EPFL), Lausanne, 2001. 164p. (Doctor ès Sciences - Thesis).

DUARTE, E.A.C., MOORHOUSE, A., VIVEIROS, E.B. Indirect measurement of acoustic power into a small room at low frequencies. Applied Acoustics, v. 73, p. 248-255, 2012

GERGES, S.N.Y. Ruído, fundamentos e controle. $2^{\text {a }}$ ed. Florianópolis: UFSC, 2000. 696 p. (in Portuguese)

HASSAN, O.A.B. Building acoustics and vibrations: theory and practice. Singapore: World Scientific, 2009.972p.

KNUDSEN V.O., HARRIS C.M. Acoustical designing in architecture. New York: The Acoustical Society of America, 1978. 408p.

MAECKAWA, Z., RINDEL, J.H, LORD, P. Environmental and architectural acoustics. 2nd ed. New York: CRC Press, 2011. 376p.

MEHTA, M., JOHNSON, J., ROCAFORT, J. Architectural acoustics: principles and design. New Jersey, Prentice Hall, 1999. 446p.

RIBAS, R.A.J., SOUZA, H.A. Acoustic performance of closing panels used in steel structure buildings. In: INTERNATIONAL CONGRESS ON SOUND \& VIBRATION, 18, 2011. Rio de Janeiro. Proceedings....p. 1-8. In: E.M., Ricardo, C. F., Raphael, B.M., Roberto (Ed.).

SALES, U.C. Mapeamento dos problemas gerados na associação entre sistemas de vedação e estrutura metálica e caracterização acústica e vibratória de painéis de vedação. Ouro Preto: Escola de Minas da Universidade Federal de Ouro Preto, 2001. 249 p. (Dissertação de Mestrado em Engenharia Civil). (in Portuguese)

SHARP, B.H. A study of techniques to increase the sound installation of building elements. Wylie Laboratories Report WR 73-S, Prepared for Department of Housing and Urban Development, Washington, DC, Under Contract H-1095. 1973.

Received: 8 April 2014 - Accepted: 22 December 2016. 